\title{
The Dorello canal: historical development, controversies in microsurgical anatomy, and clinical implications
}

\author{
Varun R. Kshettry, M.D., ${ }^{1}$ Joung H. Lee, M.D., ${ }^{1}$ and Mario Ammirati, M.D., M.B.A. ${ }^{2}$ \\ ${ }^{1}$ Department of Neurological Surgery, Cleveland Clinic, Cleveland; and ${ }^{2}$ Dardinger Microneurosurgical Skull \\ Base Laboratory, Department of Neurological Surgery, Ohio State University Wexner Medical Center, \\ Columbus, Ohio
}

\begin{abstract}
Interest in studying the anatomy of the abducent nerve arose from early clinical experience with abducent palsy seen in middle ear infection. Primo Dorello, an Italian anatomist working in Rome in the early 1900s, studied the anatomy of the petroclival region to formulate his own explanation of this pathological entity. His work led to his being credited with the discovery of the canal that bears his name, although this structure had been described 50 years previously by Wenzel Leopold Gruber. Renewed interest in the anatomy of this region arose due to advances in surgical approaches to tumors of the petroclival region and the need to explain the abducent palsies seen in trauma, intracranial hypotension, and aneurysms. The advent of the surgical microscope has allowed more detailed anatomical studies, and numerous articles have been published in the last 2 decades. The current article highlights the historical development of the study of the Dorello canal. A review of the anatomical studies of this structure is provided, followed by a brief overview of clinical considerations. (http://thejns.org/doi/abs/10.3171/2012.11 FOCUS12344)
\end{abstract}

KEY WORDS • Dorello canal • abducent nerve • petroclival region •
microsurgical anatomy

I $\mathrm{N}$ the early 1900 s, there was considerable debate regarding the origin of abducent palsy seen with acute or chronic middle ear infections. In 1904, Giuseppe Gradenigo (1859-1926), an Italian otolaryngologist, described a syndrome characterized by a triad of middle ear infection, ipsilateral abducent paralysis, and ipsilateral trigeminal neuropathic pain most commonly manifested as retroorbital pain due to irritation of the ophthalmic division of the trigeminal nerve. ${ }^{14-16}$ The mechanism of abducent palsy was vehemently debated among his contemporaries. Gradenigo himself believed that inflammation of the tympanic cavity spread to the leptomeninges,,$^{14,17}$ although he was uncertain of the mechanism whereby this occurred. In 1905, an Italian anatomist, Primo Dorello (1872-1963), offered his own theory on the possible cause of abducent nerve palsy in Gradenigo syndrome based on anatomical dissections done to study the course of the abducent nerve. ${ }^{13}$

\footnotetext{
Abbreviations used in this paper: DMA = dorsal meningeal artery; ICA = internal carotid artery; IPS = inferior petrosal sinus; $\mathrm{PVC}=$ petroclival venous confluence.
}

\section{Historical Development}

Primo Dorello was born in 1872 in Narni, Italy ${ }^{14} \mathrm{He}$ obtained his degree in medicine and surgery in Rome in 1897 and remained there as an Assistant Professor in the Department of Normal Human Anatomy. It was during his stay in Rome that he published his paper, "Considerations on the cause of transient paralysis of the abducent in middle ear inflammation." 13 Dorello described a bony prominence at the petrous apex called the spina sphenoidalis. Just medial to this structure is a depression in the sphenoid bone. The lateral side of the depression contains the petrosphenoidal suture, and the medial side is bounded by the upper outer margin of the lamina quadrangularis (now referred to as the clivus). This depression forms a canal whose superior margin is formed by the ligamentum petrosphenoidale described earlier by Gruber. ${ }^{18}$ The ligament runs from the spina sphenoidale to a subtle bony prominence just below the processus clinoidei posticus (posterior clinoid process), which Dorello termed the accessory process of the posterior clinoid. ${ }^{13,17,37}$

The dissections performed by Dorello, prior to the 
advent of the surgical microscope, revealed that the inferior petrosal sinus and abducent nerve run through this canal. He believed that the canal represents a fixed space in which inflammatory edema can compress the nerve and postulated a vascular mechanism for inflammatory extension to this region in the setting of middle ear infection. Dorello argued that the veins of the tympanic cavity are continuous with the petrosal sinuses and provide a conduit for direct spread of inflammation. He cited the work of Adam Politzer, an Austrian otologist, who described the technique of injecting middle ear veins indirectly through injection of the petrosal and transverse sinuses.14,28 Although initially disputed by Gradenigo, Dorello's work was affirmed by multiple contemporaries, and Gradenigo later modified his theory to align with the work of Dorello. 5,6,14,17

Primo Dorello was appointed to the Chair of Human Anatomy at Perugia, Italy, in 1926 and remained there until 1946. His interests were broad and included anthropology and photography. He produced 1674 stereoscopic negatives on glass of Italian architecture and city landscapes. ${ }^{14}$ In 1939, he was nominated for the Nobel Prize in Physiology or Medicine (http://www.nobelprize. org/nobel_prizes/medicine/nomination/nomination. php?action=show\&showid=495).

Although credited with the discovery of this canal, Dorello was not the first to describe it. In 1859, Wenzel Gruber described a fibrous ligament that extends from the petrous apex to the lateral dorsum sellae and creates a canal containing the abducent nerve. ${ }^{18}$

\section{Controversies in Microsurgical Anatomy}

Relatively little was published on the anatomy of the petroclival region after Dorello's time until recent developments in the surgical treatment of petroclival tumors led to renewed interest in the anatomy of the region. .,2,30,31 $^{2}$ Additionally, reports of abducent palsy associated with blunt trauma, hydrocephalus, intracranial hypotension, and aneurysm further increased interest in studying the course of the abducent nerve as a means of explaining the etiology of these clinical entities. Table 1 summarizes the literature on microsurgical anatomical studies of the Dorello canal.

\section{Description, Anatomical Boundaries, and Dimensions of the Dorello Canal}

The introduction of the operating microscope in the latter half of the 20th century has allowed more detailed anatomical study. In 1991, Umansky et al..$^{36}$ performed the first anatomical study of the Dorello canal in human cadavers using a microscope. Their description of the canal was consistent with Primo Dorello's original definition (referred to as the classic definition in Table 1), as the space between the petrous apex and the superolateral portion of the clivus bounded superiorly by the petrosphenoidal ligament of Gruber (Fig. 1). Since 1991, there have been numerous anatomical studies of the Dorello canal, 11,19,20,26,27,35 and some authors have argued for a revised definition. In 1997, Destrieux et al. ${ }^{11}$ found specimens in which the abducent nerve ran superior to the Gruber liga- ment; these authors therefore argued for a broader definition of the canal to accommodate the observed variations in the course of the nerve. Destrieux et al. ${ }^{11}$ argued for the term "petroclival venous confluence" (PVC), rather than Dorello canal and defined this space more broadly as the area between the inner (meningeal) and outer (periosteal) layers of the dura mater between the petrous apex and the margin of the sphenoid bone just below the posterior clinoidal process. Beside Dorello's canal and other structures, the PVC contains this dural venous sinus, which is fed by the posterior cavernous sinus, lateral basilar sinus, and superior petrosal sinus and empties into the inferior petrosal sinus (Figs. 2 and 3). Dolenc and Yaşargil ${ }^{12}$ argued that the Dorello canal is not even a canal in the true sense because it is not surrounded by bony walls like the optic canal, for example. He defined the boundaries as the larger space between the dural leaflets starting from the point where the abducent nerve pierces the dura to its entry into the cavernous sinus. Table 1 lists the dimensions of the Dorello canal in the published anatomical studies. Studies that utilized the term "petroclival venous confluence" generally did not provide any dimensions for the canal because, according to this concept, certain boundaries of this space consist of virtual planes.

\section{Anatomy of the Gruber Ligament}

All studies describe the Gruber ligament as butterfly shaped and silver in color. Four studies provide a mean length of the ligament, varying from 11.5 to 13.3 $\mathrm{mm} .{ }^{19,20,35,36}$ Five studies with a total of 208 specimens describe variations in the ligament, ${ }^{11,19,20,37,36}$ which was ossified in 13 specimens $(6.3 \%)$ and hypoplastic in 7 (3.4\%). ${ }^{11,19,20,35,36}$ Only 2 studies mention duplication of the ligament in $5 \%-15 \%$ of specimens. ${ }^{35,36}$ Iaconetta et al. ${ }^{19}$ found that the Gruber ligament was in continuity with the petrolingual ligament. This ligament runs from the petrous apex to the lingual process of the sphenoid bone at the foramen lacerum ${ }^{20,40,41}$ and covers the lacerum segment of the carotid artery. Iaconetta et al. ${ }^{19}$ refer to the combined petrosphenoidal and petrolingual ligament as the falciform ligament. When the Gruber ligament was mentioned, all studies described it as being immersed in venous blood.

\section{Course of the Abducent Nerve}

Five studies describe the relation of the abducent nerve to the Gruber ligament, with the nerve coursing inferior to the ligament in $89(98.9 \%)$ of 90 specimens. ${ }^{11,26,27,35,36}$ Three studies provide the position of the abducent nerve in the canal. ${ }^{27,35,36}$ It was located in the medial third in $2(4.2 \%)$ of 48 specimens, the middle third in $15(31.2 \%)$ of 48 , and the lateral third in $31(64.6 \%)$ of 48 specimens. Three studies describe duplication of the abducent nerve in $13(8.8 \%)$ of 148 specimens. ${ }^{11,19,36}$ In Iaconetta's sample of 100 specimens, the abducent nerve was duplicated at the origin in 2 specimens while in 6 specimens the nerve arose as 1 trunk, which then divided into 2 roots that separately pierced the dura to enter the Dorello canal. In all 8 cases, the split roots fused to enter the cavernous sinus as a single nerve. ${ }^{19}$ This finding 


\section{Dorello canal}

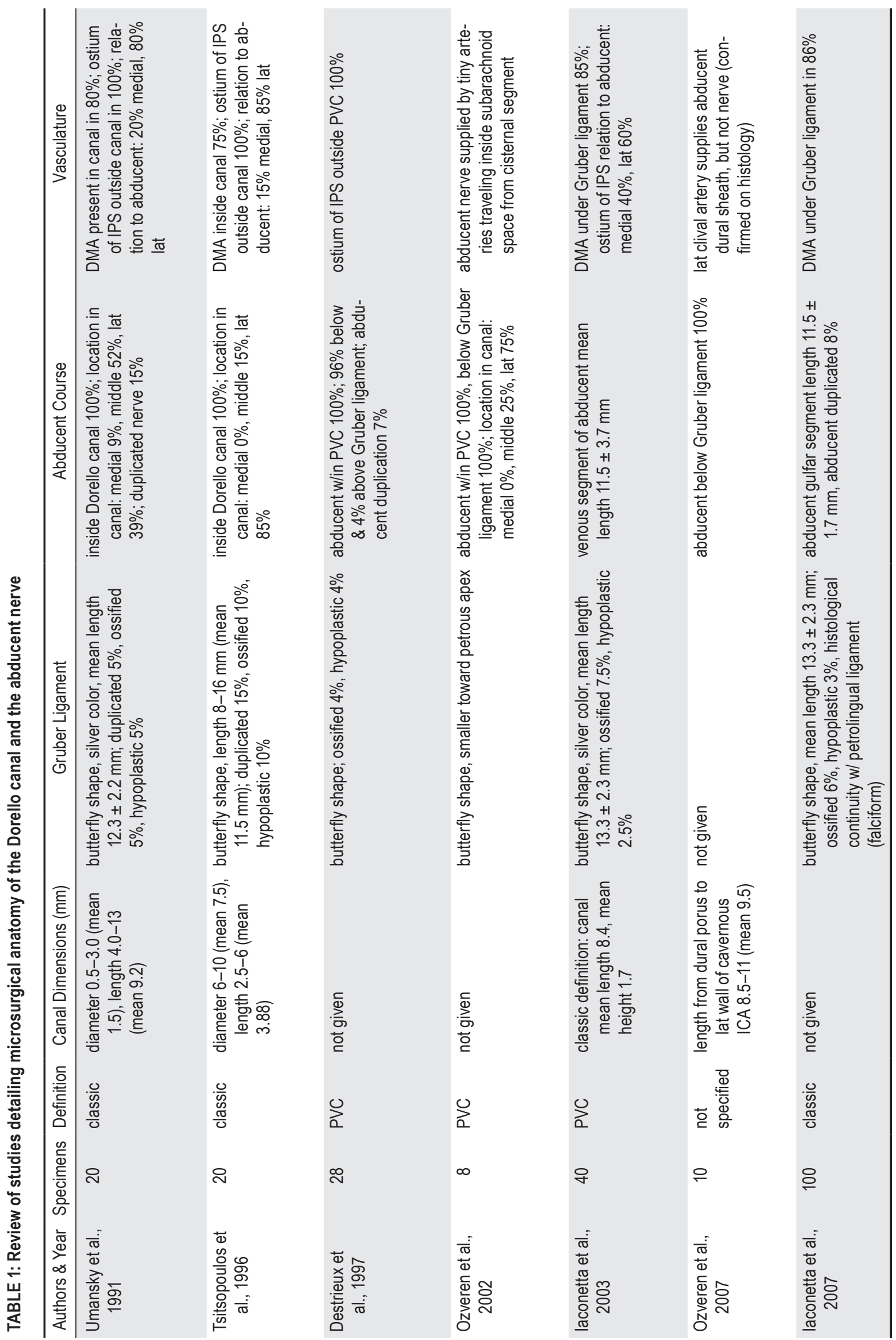



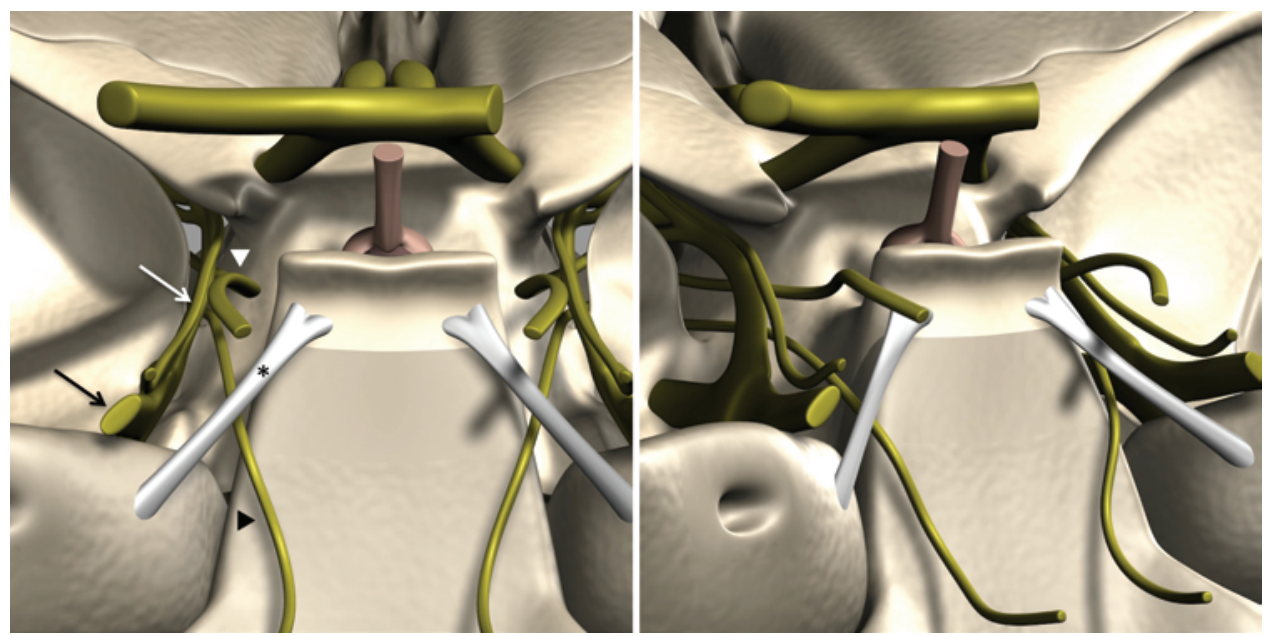

FIG. 1. Rotated 3D computer graphic views of the Dorello canal as the space between the petrous apex and superolateral portion of the clivus bounded superiorly by the petrosphenoidal ligament of Gruber (asterisk, left). Also depicted are cranial nerves III (white arrowhead), IV (white arrow), V (black arrow), and VI (black arrowhead).

is consistent with a large study done by Jain ${ }^{21}$ in 1964 , which found that the abducent nerve was duplicated in $18(6 \%)$ of 300 cases. In all of these aberrant cases, the 2 rootlets arose separately at their ventral pontine origin, generally as a larger medial root and a smaller lateral accessory root. In 17 of 18 cases, the rootlets merged in the cavernous sinus. Only in 1 case did the roots remain separated in their entire course, even penetrating the lateral rectus muscle separately. Another study by Nathan et al. ${ }^{25}$ in 1974 found duplication of the abducent nerve in 9 (14.5\%) of 62 specimens. In 4 cases $(6.5 \%)$, the abducent nerve originated as a single trunk, and then immediately divided into 2 roots that pierced the dura separately. In 5 cases $(8.1 \%)$, the nerve emerged from the pons as 2 roots that pierced the dura separately. In all 9 cases of duplication, 1 root ran above and 1 ran below the Gruber ligament, and in all cases the roots fused in the cavernous sinus. In summary, abducent nerve duplication was found in $35(7.6 \%)$ of a total of 462 specimens described in the literature. When duplication occurred, 2 roots emerged at the pontine origin in $25(71 \%)$ of 35 specimens, and a single root split into 2 rootlets within the pontine cistern in $10(29 \%)$ of 35 specimens. Duplicated roots fused into a single nerve in the cavernous sinus in 34 (97\%) of 35 cases.

The abducent nerve was covered by a dural sheath in all anatomical studies. Histological studies demonstrate that, at its entry at the dural porus, the nerve carries with it a dural sheath and an arachnoid membrane containing its blood supply from the cisternal segment of the nerve. ${ }^{26,27}$ The dural sheath has multiple connective tissue attachments to the Gruber ligament, the endosteal dura of the PVC, the lateral wall of the cavernous ICA, and

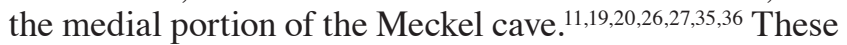
attachments limit the mobility of the nerve in compressive or stretch injuries. One study directly measured the length of the abducent nerve through the PVC at a mean of $11.5 \pm 3.7 \mathrm{~mm} .{ }^{20}$

\section{Vasculature of the Dorello Canal}

Arterial supply to the petroclival region is provided
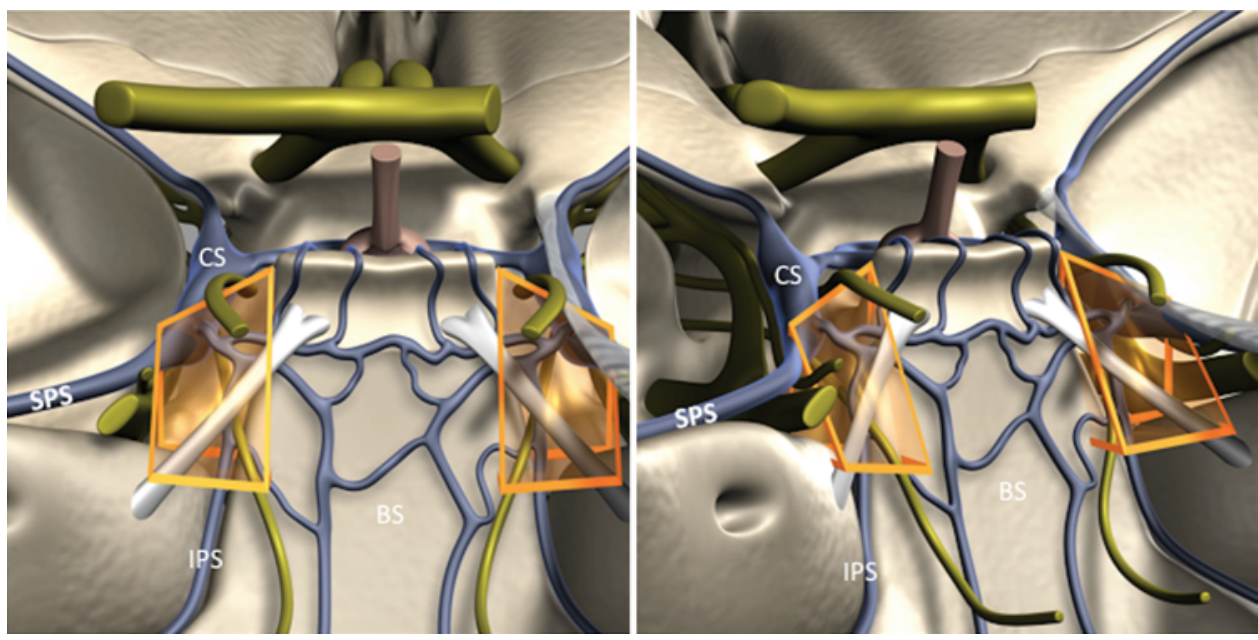

FIG. 2. Rotated 3D computer graphic views of the anatomy of the PVC (orange area), which is fed by the posterior cavernous sinus (CS), lateral basilar sinus (BS), and superior petrosal sinus (SPS) and which empties via the IPS. 


\section{Dorello canal}
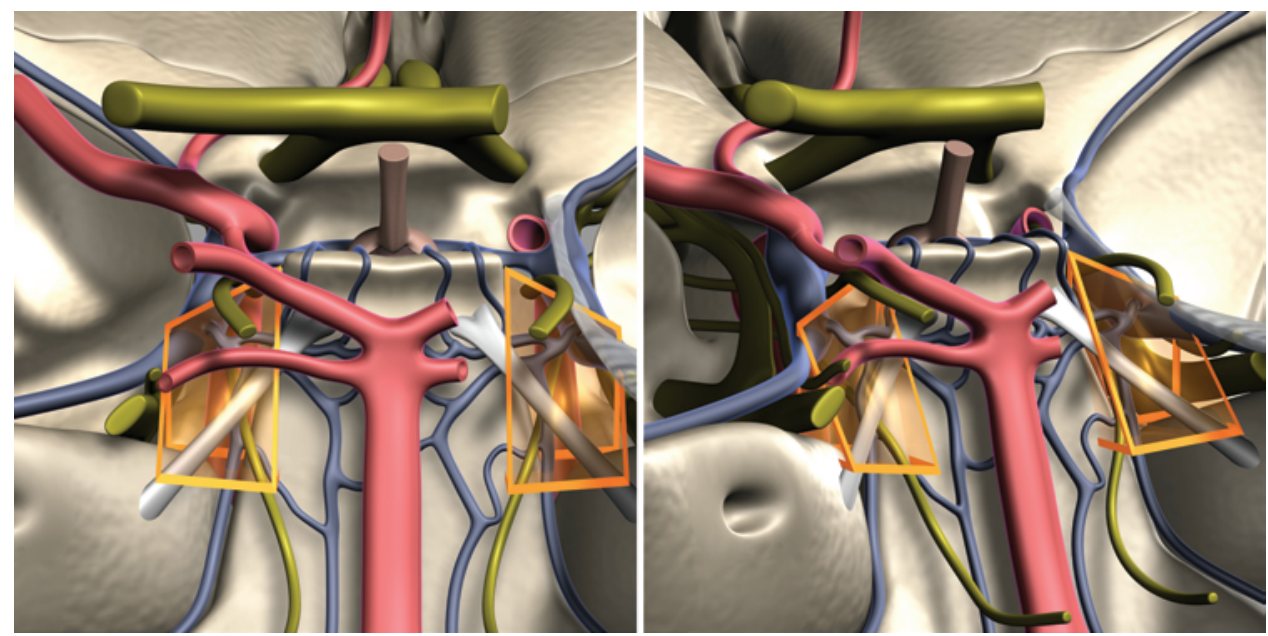

FIG. 3. Rotated 3D computer graphic views of the PVC (orange area). The PVC is bounded superiorly by the posterior petroclinoidal dural fold, inferiorly just below the dural porus of the abducent nerve, medially by the IPS-BS junction, and laterally by the medial petrous apex. Superiorly, the PVC is bound by a single plane. Inferiorly, the PVC extends anterior to posterior from the posterior CS to the posterior wall of the IPS.

by branches from the posterior bend of the cavernous ICA. Studies generally describe a meningohypophysial trunk that branches into an inferior hypophysial artery, tentorial artery, and meningeal branches. The meningeal branches consist of a medial clival artery (DMA) and a lateral clival artery. All studies indicate that the medial clival artery travels to supply the dura of the dorsum sellae and upper clivus. The lateral clival artery supplies the lateral petroclival dura and the dural sleeve of the abducent nerve. Initial studies indicated that the lateral clival artery directly supplies the abducent nerve, but histological analysis done by Ozveren et al. ${ }^{26,27}$ demonstrates that the lateral clival artery only supplies the dural sheath of the nerve. Blood supply for the actual nerve comes from tiny arteries arising from the subarachnoid space that travel in an invaginated arachnoid membrane where the nerve penetrates the dura. In some specimens, the clival arteries originate directly off the cavernous ICA. Four studies explicitly describe the relationship of the DMA to the Gruber ligament. The DMA traveled under the Gruber ligament in 151 (83.9\%) of 180 specimens. ${ }^{19,20,35,36}$

Although Dorello included the IPS within the canal in his original description, all studies done using the operating microscope have demonstrated that the ostium of the IPS is outside of the canal. Three studies explicitly describe the relationship of the ostium of the IPS in relation to the abducent nerve..$^{20,35,36}$ The ostium of the IPS is lateral to the abducent nerve in $57(71.3 \%)$ of 80 specimens and medial to it in 23 (28.8\%) of 80 specimens.

\section{Clinical Implications}

Initial interest in studying the anatomy of the abducent nerve arose from the occurrence of abducent palsy in clinical practice. Abducent nerve palsies have been described in trauma with or without fractures of the skull base, ${ }^{4,32-34}$ mass effect with brainstem shift, ${ }^{38}$ ICA aneurysms, ${ }^{3,31}$ intracranial hypotension, ${ }^{9}$ lumbar puncture, ${ }^{23,39}$ shunting for hydrocephalus, ${ }^{10}$ sphenoid sinus pathology, and suppurative middle ear infections. ${ }^{16}$ While direct injury or compression is straightforward, the etiology of indirect injuries or stretch injuries in trauma or intracranial hypotension is more peculiar. Some have hypothesized as to why the abducent nerve may be sensitive to injury in such cases. Umansky et al. ${ }^{36}$ described 3 curves in the course of the abducent nerve. The first occurs at the dural foramen where the nerve courses laterally toward the petrous apex. The second curve extends over the petrous apex after which the nerve angles inferiorly and laterally to reach the posterior bend of the cavernous ICA. The last curve is around the posterior bend of the ICA. Of these, the most severe curve occurs over the petrous apex and would, therefore, be the point most vulnerable to blunt trauma or stretch injury. Iaconetta et al. ${ }^{19}$ point out that there is a point of fixation at the dural porus. In cases of intracranial hypotension with brainstem sag or cervical trauma resulting in parenchymal movement within the cranium, this may be a point at which the cisternal segment of the nerve suffers stretch injury. ${ }^{9}$ Ozveren et al..$^{27}$ point out that fixation of the nerve to the lateral wall of the cavernous ICA may also be a mechanism for abducent nerve injury in trauma. An autopsy analysis after severe head trauma demonstrated frequent contusion at this site and at the dural porus.

Knowledge of the detailed anatomy of the abducent nerve is of utmost importance to minimize risk of injury in surgical approaches to the petroclival region. The advent of endoscopic endonasal transclival, transellar transcavernous, and paramedian approaches to the medial petrous apex has renewed interest in studying the anatomical relations of the abducent nerve from an endoscopic perspective. ${ }^{7,22}$ In particular, petroclival tumors tend to grow along a lateral to medial trajectory and can therefore displace the abducent nerve medially. BargesColl et al. ${ }^{7}$ found that the vertebrobasilar junction was on average $4 \mathrm{~mm}$ inferior to the origin of the abducent nerve and served as a good landmark for the cisternal segment in midline approaches. In the lateral transclival and medial petrous apex approaches, the dural entry point of the 
abducent nerve is just posterosuperior to the upper limit of the lacerum segment of the ICA $\left(\mathrm{C}_{3}\right)$, and the nerve is at risk for direct or thermal injury during drilling. ${ }^{7}$ In the posterior cavernous sinus, the abducent nerve runs parallel to the V1 segment of the trigeminal nerve, and therefore, dissection in the approach via the Meckel cave should not proceed above the V2 segment. ${ }^{7}$ Abducent nerve injury during endoscopic endonasal approaches has been well documented. ${ }^{7,24}$

\section{Conclusions}

The anatomy of the abducent nerve in the petroclival region helps explain abducent palsies seen in clinical practice. Knowledge of the relationships between bony landmarks, venous sinus anatomy, and cranial nerves is critical for safe surgery in this area. Additionally, familiarity with anatomical variations enhances surgical knowledge.

\section{Disclosure}

The authors report no funding or conflict of interest concerning the materials or methods used in this study or the findings specified in this paper.

Author contributions to the study and manuscript preparation include the following. Conception and design: Kshettry. Acquisition of data: Kshettry. Analysis and interpretation of data: Kshettry. Drafting the article: Kshettry. Critically revising the article: all authors. Reviewed submitted version of manuscript: all authors. Approved the final version of the manuscript on behalf of all authors: Ammirati. Statistical analysis: Kshettry. Administrative/technical/ material support: Lee. Study supervision: Ammirati.

\section{Acknowledgments}

The authors greatly appreciate Mark Sabo, B.F.A., and the Medical Art Department at the Cleveland Clinic for the development of the graphics for the manuscript.

\section{References}

1. Al-Mefty O, Fox JL, Smith RR: Petrosal approach for petroclival meningiomas. Neurosurgery 22:510-517, 1988

2. Ammirati M, Samii M: Presigmoid sinus approach to petroclival meningiomas. Skull Base Surg 2:124-128, 1992

3. Anderson RD, Liebeskind A, Schechter MM, Zingesser LH: Aneurysms of the internal carotid artery in the carotid canal of the petrous temporal bone. Radiology 102:639-642, 1972

4. Arias MJ: Bilateral traumatic abducens nerve palsy without skull fracture and with cervical spine fracture: case report and review of the literature. Neurosurgery 16:232-234, 1985

5. Baldenweck L: Recherches anatomiques sur la pointe de rocher. Annales des maladies de l'oreille du larynx, du nez et du pharynx 33:122, 1907

6. Baratoux J: La paralysie du moteur oculaire externe au cours des otites. Archives internationales de laryngologie, d'otologie et de rhinologie. Paris: JB Baillilli et fils, 1907

7. Barges-Coll J, Fernandez-Miranda JC, Prevedello DM, Gardner P, Morera V, Madhok R, et al: Avoiding injury to the abducens nerve during expanded endonasal endoscopic surgery: anatomic and clinical case studies. Neurosurgery 67:144154,2010

8. Bennett M: Unilateral abducens paralysis in primary neoplastic disease of the sphenoid sinus. Laryngoscope 74:272-294, 1964

9. Berlit P, Berg-Dammer E, Kuehne D: Abducens nerve palsy in spontaneous intracranial hypotension. Neurology 44:1552, 1994

10. Black PM, Chapman PH: Transient abducens paresis after shunting for hydrocephalus. Report of two cases. J Neurosurg 55:467-469, 1981

11. Destrieux C, Velut S, Kakou MK, Lefrancq T, Arbeille B, Santini JJ: A new concept in Dorello's canal microanatomy: the petroclival venous confluence. J Neurosurg 87:67-72, 1997

12. Dolenc V, Yaşargil MH: Anatomy and Surgery of the Cavernous Sinus. New York: Springer-Verlag, 1989, pp 68-87

13. Dorello P: Considerazioni sopra la causa della paralisi transitoria dell'abducente nelle flogosi dell'orecchio medio, in Ferreri G (ed): Atti Della Clinica Oto-Rino-Laringoiatrica. Roma: Tipografia del Campidoglio, 1905, pp 209-217

14. Felisati D, Sperati G: Gradenigo's syndrome and Dorello's canal. Acta Otorhinolaryngol Ital 29:169-172, 2009

15. Gradenigo G: Sur un syndrome particulier des complications endocraniennes otitiques: paralysie de l'abducteur d'origine otitique. Annales des maladies de l'oreille, du larynx, du nez et du pharynx 30:120-152, 1904

16. Gradenigo G: Uber circumscripte Leptomeningitis mit spinalen Symptomen and uber Paralyse des N. abducens otitischen Ursprungs. Arch Ohrenheilk 62:255-270, 1904

17. Gradenigo G: Uber die Paralyse des Nervus abducens bei Otitis. Archiv Uhrenheil 74:149-187, 1907

18. Gruber W: Beiträge zur Anatomie des Keilbeins und Schläfenbeins, in Richter HE, Winter A (eds): Schmidt's Jahrbücher der In- und Ausländischen Gesammten Medicin. II. Anatomie und Physiologie. Leipzig: Verlag Von Otto Wigard, 1859

19. Iaconetta G, Fusco M, Cavallo LM, Cappabianca P, Samii M, Tschabitscher M: The abducens nerve: microanatomic and endoscopic study. Neurosurgery 61 (3 Suppl):7-14, 2007

20. Iaconetta G, Fusco M, Samii M: The sphenopetroclival venous gulf: a microanatomical study. J Neurosurg 99:366375,2003

21. Jain KK: Aberrant roots of the abducent nerve. J Neurosurg 21:349-351, 1964

22. Kassam A, Snyderman CH, Mintz A, Gardner P, Carrau RL: Expanded endonasal approach: the rostrocaudal axis. Part I. Crista galli to the sella turcica. Neurosurg Focus 19(1):E3, 2005

23. Khemka S, Mearza AA: Isolated sixth nerve palsy secondary to spontaneous intracranial hypotension. Eur J Neurol 13:1264-1265, 2006

24. Kim HD, Lim SC: Transient abducens nerve palsy during endoscopic sinus surgery: report of three cases. Auris Nasus Larynx 34:237-239, 2007

25. Nathan H, Ouaknine G, Kosary IZ: The abducens nerve. Anatomical variations in its course. J Neurosurg 41:561-566, 1974

26. Ozveren MF, Erol FS, Alkan A, Kocak A, Onal C, Ture U: Microanatomical architecture of dorello's canal and its clinical implications. Neurosurgery 60:ONS1-ONS8, 2007

27. Ozveren MF, Uchida K, Tekdemir I, Cobanoglu B, Akdemir I, Kawase T, et al: Dural and arachnoid membraneous protection of the abducens nerve at the petroclival region. Skull Base 12:181-188, 2002

28. Politzer A: La dissection anatomique et histologique de l'organe auditif de l'homme à l'état normal et pathologique à l'usage des anatomistes, des médecins auristes et des étudiants. Schiffer F, trans. Paris: Charles Desoer, 1898

29. Samii M, Ammirati M: The combined supra-infratentorial pre-sigmoid sinus avenue to the petro-clival region. Surgical technique and clinical applications. Acta Neurochir (Wien) 95:6-12, 1988

30. Samii M, Ammirati M, Mahran A, Bini W, Sepehrnia A: Surgery of petroclival meningiomas: report of 24 cases. Neurosurgery 24:12-17, 1989 


\section{Dorello canal}

31. Sarwar M: Abducens nerve paralysis due to giant aneurysm in the medial carotid canal. Case report. J Neurosurg 46:121123, 1977

32. Schneider RC, Johnson FD: Bilateral traumatic abducens palsy. A mechanism of injury suggested by the study of associated cervical spine fractures. J Neurosurg 34:33-37, 1971

33. Summers CG, Wirtschafter JD: Bilateral trigeminal and abducens neuropathies following low-velocity, crushing head injury. Case report. J Neurosurg 50:508-511, 1979

34. Takagi H, Miyasaka Y, Kuramae T, Ohwada T, Tsunoda M: [Bilateral traumatic abducens nerve palsy without skull fracture or intracranial hematoma-a report of 3 cases and consideration of the mechanism of injury (author's transl).] No Shinkei Geka 4:963-969, 1976 (Jpn)

35. Tsitsopoulos PD, Tsonidis CA, Petsas GP, Hadjiioannou PN, Njau SN, Anagnostopoulos IV: Microsurgical study of the dorello's canal. Skull Base Surg 6:181-185, 1996

36. Umansky F, Elidan J, Valarezo A: Dorello's canal: a microanatomical study. J Neurosurg 75:294-298, 1991

37. Vail H: Anatomical studies of dorello's canal. Laryngoscope 32:569-575, 1922

38. Wolff E: A bend in the sixth cranial nerve-and its probable significance. Br J Ophthalmol 12:22-24, 1928
39. Yaman ME, Ayberk G, Eylen A, Ozveren MF: Isolated abducens nerve palsy following lumbar puncture: case report and review of the mechanism of action. J Neurosurg Sci 54:119123,2010

40. Ziyal IM, Ozgen T: The abducens nerve: Microanatomic and endoscopic study. Neurosurgery 63:E820, 2008 (Letter)

41. Ziyal IM, Salas E, Wright DC, Sekhar LN: The petrolingual ligament: the anatomy and surgical exposure of the posterolateral landmark of the cavernous sinus. Acta Neurochir (Wien) 140:201-205, 1998

Manuscript submitted October 16, 2012.

Accepted November 26, 2012.

Please include this information when citing this paper: DOI: 10.3171/2012.11.FOCUS12344.

Address correspondence to: Mario Ammirati, M.D., M.B.A., Department of Neurological Surgery, Ohio State University Wexner Medical Center, N1025 Doan Hall, 410 West 10th Avenue, Columbus, Ohio 43210. email: mario.ammirati@osumc.edu. 